\title{
257. Chlorogenic Acid Promotes the Utilization of Oil in the Growth of Silkworm*)
}

\author{
By Masaru Kato and Hiromi Yamada \\ Department of Zoology, Faculty of Science, Kyoto University \\ (Comm. by Eikiti Hiratsuka, M.J.A., Dec. 12, 1966)
}

Hamamura and his coworkers ${ }^{1,2)}$ proposed a menu of synthetic diet for silkworm, Bombyx mori, based on their studies on the feeding mechanism of this insect. This menu was considerably improved recently by the addition of chlorogenic acid which induces a more natural growth of the larvae. ${ }^{3)}$ The same effect was looked for several other kinds of oil of plant or animal origin. And, it has been confirmed that the effects of these various oils on the larval growth may be considerably promoted in the presence of chlorogenic acid. Also, it has been found that both cottonseed oil and peanut oil have greater effect than soybean oil. ${ }^{4)}$

Materials and methods. The $F_{1}$ of the cross of the strains Gunko and Manri, kindly provided by Gunze Silk Co., was used throughout the experiment.

The composition of the basal synthetic diet is shown in Table I. Instead of chlorogenic acid in crystalline state, the chlorogenic acid obtained from mulberry leaves was added to the diet. The method of preparation was as follows:- $100 \mathrm{~g}$. of the leaf powder is extracted with 11 . of $80 \%$ aqueous methanol, and the extract is

Table I. Composition of the basal synthetic diet

\begin{tabular}{lc}
\hline Component & g. per 10g. dry weight \\
\hline Cellulose powder & 5.2 \\
Soybean protein & 2.0 \\
Potato starch & 1.5 \\
Sucrose & 1.0 \\
Wesson's salt mixture & 0.09 \\
Vitamin mixture* & 0.04 \\
Chlorogenic acid & 0.10 \\
Inositol $^{*} \mathrm{~K}_{4}$ & 0.05 \\
-Sitosterol & 0.05 \\
\hline
\end{tabular}

* Composition of the vitamin mixture is as in the Hayashiya's paper. ${ }^{2)}$ To $10 \mathrm{~g}$. of dry diet, $15 \mathrm{ml}$. of water is added to prepare diet paste.

*) No. 20 of the joint studies on artificial diet for the silkworm Bombyx mori by Hamamura et al. 
concentrated to syrup. To this, $200 \mathrm{ml}$. ethyl ether and $200 \mathrm{ml}$. water are added. After complete dissolution of the substance, the water layer is separated from the ether layer. The water layer is acidified with $\mathrm{HCl}$ and then extracted with $350 \mathrm{ml}$. ethyl acetate. Thus, the concentrated chlorogenic acid is obtained by evaporation of the ethyl acetate solution. This concentration has the growth promoting activity nearly equivalent to that of crystalline chlorogenic acid..$^{3}$

The rearing of larvae was carried out under the aseptic condition, as described in the previous paper.5) All kinds of oils used in the experiment were of the "chemically pure" grade. Each oil was dissolved in ethyl ether, and mixed to the diet in $1 \%$ of the amount, prior to the preparation of the paste.

Results and discussion. The silkworm larvae fed on the basal diet containing no chlorogenic acid weighed $67.4 \mathrm{mg}$. on the average and the rate of survival was $70 \%$ on the 17 th day (Table II). The

Table II. Nutritional effect of oils on the growth of silkworm larvae

\begin{tabular}{|c|c|c|c|c|c|c|}
\hline \multirow{3}{*}{ Oil } & \multicolumn{6}{|c|}{ After 17 days } \\
\hline & \multicolumn{3}{|c|}{ Without chlorogenic acid } & \multicolumn{3}{|c|}{ With chlorogenic acid } \\
\hline & $\begin{array}{l}\text { Sur- } \\
\text { vival }\end{array}$ & $\begin{array}{c}4 \text { th } \\
\text { instar } \\
\text { appearance }\end{array}$ & $\begin{array}{c}\text { Mean } \\
\text { body } \\
\text { weight }\end{array}$ & $\begin{array}{l}\text { Sur- } \\
\text { vival }\end{array}$ & $\begin{array}{c}4 \text { th } \\
\text { instar } \\
\text { appearance }\end{array}$ & $\begin{array}{c}\text { Mean } \\
\text { body } \\
\text { weight }\end{array}$ \\
\hline None & $70 \%$ & $0 \%$ & $67.4 \mathrm{mg}$. & $84 \%$ & $24 \%$ & $113.0 \mathrm{mg}$ \\
\hline Butter & 88 & 25 & 50.0 & 78 & 52 & 238.0 \\
\hline Cocoanut & 65 & 0 & 72.1 & 74 & 57 & 171.0 \\
\hline Whale & 45 & 6 & 98.4 & 27 & 18 & 309.0 \\
\hline Cottonseed & 86 & 10 & 114.2 & 72 & 60 & 515.0 \\
\hline Rapeseed & 62 & 0 & 20.8 & 83 & 17 & 88.0 \\
\hline Soybean & 84 & 5 & 87.3 & 92 & 67 & 269.0 \\
\hline Camellia & 60 & 0 & 41.9 & 96 & 44 & 109.5 \\
\hline Olive & 70 & 0 & 34.8 & 96 & 68 & 248.0 \\
\hline Peanut & 67 & 7 & 59.6 & 81 & 77 & 517.0 \\
\hline Sesame & 46 & 0 & 26.5 & 84 & 46 & 153.5 \\
\hline Cod liver & 96 & 14 & 99.9 & 48 & 33 & 251.0 \\
\hline Linseed & 72 & 0 & 42.2 & 89 & 58 & 216.0 \\
\hline Castor & 50 & 0 & 12.8 & 65 & 0 & 16.7 \\
\hline
\end{tabular}

In each experiment, 25 newly hatched larvae were used.

administration of the improved diet containing chlorogenic acid raised the weight to $113.0 \mathrm{mg}$. and the survival rate to $84 \%$.

The addition of cottonseed oil, soybean oil, or cod-liver oil to the basal diet also caused some improvement in growth. Of these, the cottonseed oil worked best and raised the mean body weight by 17day feeding to $114.2 \mathrm{mg}$; ; also the survival rate in the 4 th-instar 
larvae was significantly increased. Cod-liver oil and soybean oil also contributed to raise the rate of survival and to the rate of the appearance of the 4th instar, and the body weight became 99.9 and $87.3 \mathrm{mg}$. respectively on the average.

When the chlorogenic acid was added to the basal diet, the growth effect of cottonseed oil was remarkably promoted, so much so that the mean body weight after the 17-day feeding bacame $515.0 \mathrm{mg}$., which is almost $70 \%$ of the level in the freshleaf feeding, and $80 \%$ of the surviving larvae reached the 4th instar (Table II). Peanut oil is comparable in effect to cottonseed oil in the presence of chlorogenic acid. It is an interesting fact that peanut oil has no significant activity in the absence of chlorogenic acid. On the other hand, only small growth promoting effect of chlorogenic acid has been shown for soybean oil, being barely a half the effect of cotton seed oil or peanut oil. Butter, olive, and linseed oils had the effect of about the same level as that of soybean oil in growth promoting activity. Cod-liver oil rather lowered the survival rate, although growth was remarkably promoted in the presence of chlorogenic acid. Rapeseed and castor oils were always inhibitory to the larval growth, and whale oil decreased the number of surviving larvae particularly. Nevertheless, the chlorogenic acid seemed to have increased their growth rate to some extent.

The active factor in cottonseed, peanut, or in other oils has not been determined yet. Ito et $\left.a l_{0}{ }^{6}\right)$ have suggested the active factor in soybean oil as to be a sterol. The basal diet used in the present experiment, however, contained a sufficient amount of mulberry sterol, $\beta$-sitosterol. Therefore, it is more likely that some still unknown fat-soluble growth promoting factor is present in those oils. Further studies on this line may be able to make out the promoting mechanism of the chlorogenic acid in all these oils.

Summary. The nutritional effects of several kinds of oils of plant or animal origin on the larval growth of silkworm, Bombyx mori, were examined. It has been found that chlorogenic acid considerably fortifies the growth promoting effect of various oils, and also that cottonseed oil and peanut oil show a strong growth stimulating activity.

Acknowledgments. The authors express their appreciation to Drs. Y. Hamamura and K. Nakamura for their continuous encouragement, and to Misses T. Miyazaki and A. Saeki for their able technical assistance. We also are indebted to Dr. T. Komaifor reading this manuscript. 


\section{References}

1) Hamamura, Y.: Mem. of Kyoto Univ. of Ind. Tex. Fib., 3, 567 (1962).

2) Hayashiya, K., Naito, K., Matsuura, K., Nishida, J., and Hamamura, Y.: J. Agr. Chem. Soc. Japan, 37, 160 (1963).

3) Yamada, H., and Kato, M.: Proc. Japan Acad., 42, 399 (1966).

4) Ito, T.: Proc. Japan Acad., 36, 287 (1960).

5) Kato, M., and Yamada, H.: J. Silkworm (France), 85, $15-16$ (1963-1964).

6) Ito, T.: Proc. 11th Internat. Congr. Ent., 3, 157 (1960). 